Article

\title{
Development of Heat Transfer Surface Area Enhancements: A Test Facility for New Heat Exchanger Designs
}

\author{
Hannes Fugmann * (D), Paolo Di Lauro, Aniket Sawant and Lena Schnabel \\ Fraunhofer ISE, Fraunhofer Institute for Solar Energy Systems, Heidenhofstr. 2, 79110 Freiburg, Germany; \\ paolo.di.lauro@ise.fraunhofer.de (P.D.L); aniketlive@gmail.com (A.S.); lena.schnabel@ise.fraunhofer.de (L.S.) \\ * Correspondence: hannes.fugmann@ise.fraunhofer.de; Tel.: +49-761-4588-5527
}

Received: 3 May 2018; Accepted: 19 May 2018; Published: 22 May 2018

\begin{abstract}
Enhancing the heat transfer surface by usage of cellular metal structures, such as foams or wire structures, might allow enlarging the surface area, increasing the heat transfer coefficients, decreasing the material utilization, and enabling the flexibility of different geometrical dimensions. However their manufacturing and assembling in a large heat exchanger for performance testing and optimizing can be costly. Therefore a test rig was constructed for experimental characterization of heat transfer surface area enhancements. Heat exchanger samples with dimensions in the centimeter range can be measured. The fluid flow and heat transfer features of a micro pin fin wire structure made from copper by soft-soldering were experimentally characterized under steady-state forced air convection. The results are compared to performance characteristics of louvered fins. Heat transfer coefficients of the pin fins are twice as high as for the louvered fins. The relative expanded uncertainty of the Nusselt number is $\pm 7 \%$.
\end{abstract}

Keywords: air-to-water heat exchanger; heat transfer; fluid dynamics; performance evaluation; heat transfer surface area enhancement; wire structure heat exchanger; cellular metal structure; pin fins

\section{Introduction}

In recent years the development of cellular metal structures as heat transfer surface area enhancements has intensified. These structures are attractive for a wide range of applications where dissipation of heat within relatively small spaces is demanded. The cellular metal structures can be classified into two classes, one with a stochastic topology and the other with a periodic structure [1]. Examples of a stochastic topology include metal foams and packed beds. However, these structures generally suffer from very high pressure drops due to their undirected microgeometry [2-4]. At the same time, heat flux through undirected microgeometry is inhibited. Examples of periodic cellular metal structures include materials made from stacked or corrugated metal textiles, pin fins and microtruss concepts (e.g., tetrahedral, pyramidal, or Kagome topologies) $[1,5,6]$.

The focus of this experimental study is on cellular metal structures, particularly wire structures, in gas-to-liquid heat exchangers. The heat transfer enhancement is realized on the gas side, as heat transfer is limited there; primarily due to the low thermal conductivity of gas. The heat transfer process can be compared to a process with ordinary fins, with gas flowing around the additional structure. Assuming that the gas is colder than the liquid, heat is transferred from the liquid to the fluid-separating wall primarily by convection, through the fluid-separating wall and the structure by conduction, and finally to the gas, again primarily by convection. A variety of different wire structure design ideas are given in the literature and on the market. Those include metallic woven-wire 
mesh structures [7-9] and screen-fin structures [10], which are contacted to a flat primary surface. Vision4Energy [11] is one manufacturer of an air-to-air heat exchanger with a separating plastic wall; numerical performance evaluation of that heat exchanger is done by Bonestroo [12]. Further numerical studies of pins and a comparison of the thermal and fluid dynamic performances with louvered fins are given in Sahiti [13]. The performance comparison shows that the pin fin heat exchanger is able to perform equally to a reference louvered fin heat exchanger, but with $22 \%$ less volume. Fugmann et al. [14] show the potential for a set of parallel wire structures based on computational fluid dynamics (CFD) simulation.

As the manufacturing of these new structures is demanding and a variation of geometry is often necessary, manufacturing of real size heat exchangers is costly in terms of labor and investment. Thus an experimental setup for small scale samples (with air channel heights in the centimeter range) is favored over a setup for large scale samples. Smaller test rigs are accompanied with higher relative uncertainties, due to e.g., lower mass flow rates and lower heat transfer rates. Thereof limitations for performance evaluation of the heat transfer enhancement structures are given. This paper demonstrates the benefits and drawbacks of a small test rig and the possibilities for performance measurement of new structures.

A number of authors have constructed test facilities for small scale samples and show some limitations of performance analysis. Petroski [15] describes the test rig for measurement of confined, saw-tooth shaped wire-on-tube condensers with a height of channel equal to $50.8 \mathrm{~mm}$ and the width of the test section fixed at $762 \mathrm{~mm}$. Prasad [9] shows measurements for a packed bed solar absorber (wire screen matrices) with a channel height of $25 \mathrm{~mm}$. Tian et al. [1] reduce the channel height further to $10 \mathrm{~mm}$ for measurements of cellular copper structures. They vary the mean inlet air velocity from 1.0 to $10 \mathrm{~m} / \mathrm{s}$ and work out a comparison of different heat transfer surface area enhancements with an uncertainty in Nusselt number of 5\%. Kim et al. [16] examine triangulated, lightweight, aluminum lattice-frame materials (LFMs) with a channel height of $12 \mathrm{~mm}$. A non-rectangular cross section test rig is described in Hutter [3], with a $7 \mathrm{~mm}$ diameter round tube and a porous media foam inside the tube. For the applied thermocouples an accuracy of $0.5^{\circ} \mathrm{C}$ is assumed. A collection of test facility characteristics is given in Table 1.

Table 1. Characteristics of test facilities in literature for small scale heat exchanger samples; air as flow medium.

\begin{tabular}{|c|c|c|c|c|c|c|}
\hline & Present Study & Petroski [15] & Prasad [9] & Tian et al. [1] & Kim [16] & Hutter [4] \\
\hline sample height (mm) & $\begin{array}{c}8.15-10 \\
\text { (variable) }\end{array}$ & $\begin{array}{l}50.8-152 \\
\text { (variable) }\end{array}$ & 25 & 10 & 12 & 7 \\
\hline sample length (mm) & $10-30$ & 622 & 750 & 60 & 127 & 200 \\
\hline sample geometry & micro pin fin & saw-tooth & wire screen & $\begin{array}{l}\text { square, diamond } \\
\text { cells }\end{array}$ & LFM & $\begin{array}{l}\text { metal foams, } \\
\text { porous } \\
\text { media }\end{array}$ \\
\hline $\begin{array}{c}\text { temperature } \\
\text { measurement method }\end{array}$ & Pt100 + Pt106 & $\begin{array}{l}\text { thermo-couple } \\
\text { (type T) }\end{array}$ & $\begin{array}{l}\text { thermo-couple } \\
\text { (type T) }\end{array}$ & $\begin{array}{l}\text { thermo-couple } \\
\text { (type T) }\end{array}$ & $\begin{array}{l}\text { thermo-couple } \\
\text { (type T) }\end{array}$ & $\begin{array}{l}\text { thermo-couple } \\
\text { (type K) }\end{array}$ \\
\hline heating method & $\begin{array}{l}\text { electric heating } \\
\text { pad }\end{array}$ & water & $\begin{array}{l}\text { solar } \\
\text { radiation }\end{array}$ & $\begin{array}{l}\text { electric heating } \\
\text { pad }\end{array}$ & $\begin{array}{c}\text { electric } \\
\text { heating pad }\end{array}$ & $\begin{array}{l}\text { wrap-around } \\
\text { heating cord }\end{array}$ \\
\hline $\begin{array}{l}\text { uncertainty heat } \\
\text { transfer (Nusselt } \\
\text { number deviation) }\end{array}$ & $6.6 \%$ & $6.4-8.7 \%$ & $6.0 \%$ & $5.4 \%$ & $8.3 \%$ & - \\
\hline
\end{tabular}

In this study a comparison of louvered fins with a wire structure based on micro pin fins was performed. The wire diameter of the manufactured structures is in the tenth millimeter range. The lengths of the wires between two sample faces, separating the liquid side from the gas side, are in the lower centimeter range. A heat transfer coefficient of approximately $250 \mathrm{~W} /\left(\mathrm{m}^{2} \mathrm{~K}\right)$ is expected for an air flow around a single wire of $0.25 \mathrm{~mm}$ in diameter ([17], Chapter Gf) and for the micro pin fin geometry tested within this study [14] (incoming air temperature: $25^{\circ} \mathrm{C}$; velocity: $2 \mathrm{~m} / \mathrm{s}$ ). 
Two questions shall be answered within this paper: (i) What are the geometrical and operational restrictions for a performance analysis of a small scale surface area enhancement with sufficient measurement accuracy? (ii) Is it possible to confirm the simulated high potential in thermo-hydraulic performance of a micro pin fin wire structure with measurements?

\section{Test Samples}

\subsection{Louvered Fins}

Louvered fins were chosen to represent a market available geometry for an enhancement. The louvered fins serve as a reference. The copper fins in the test sample (Figure 1) have 16 louvers within a flow length of $32 \mathrm{~mm}$. With a fin pitch of $2 \mathrm{~mm}$ and a fin thickness of $0.04 \mathrm{~mm}$, this geometry reaches volume specific surface areas above $2100 \mathrm{~m}^{2} / \mathrm{m}^{3}$. Further morphological information is given in Table 2.
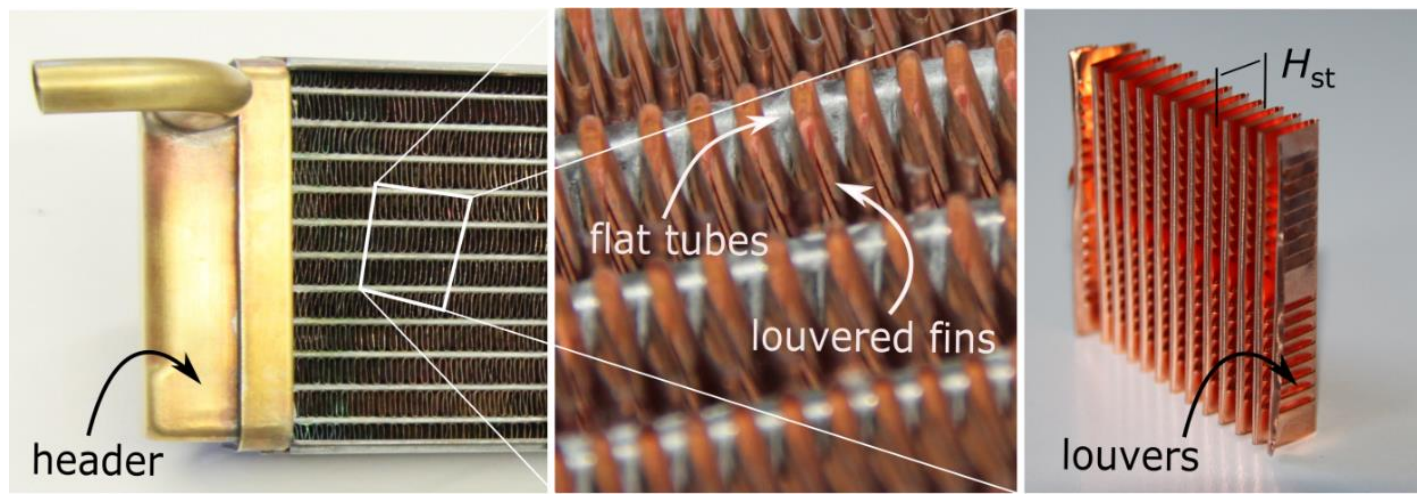

Figure 1. Air-to-water flat tube heat exchanger (left) with louvered fins between the tubes (middle);

Details of a louvered fin package used between top and bottom sample plates (right) [18].

The louvered fin package (Figure 2) is contacted to two copper (Cu-ETP) sample plates each $5 \mathrm{~mm}$ thick. Contacting is done with a soft solder paste based on alloy Sn97Cu3 with the flux material colophony. The sample plates have drilled holes $(\varnothing 1.4 \mathrm{~mm})$ for temperature sensors positioning.

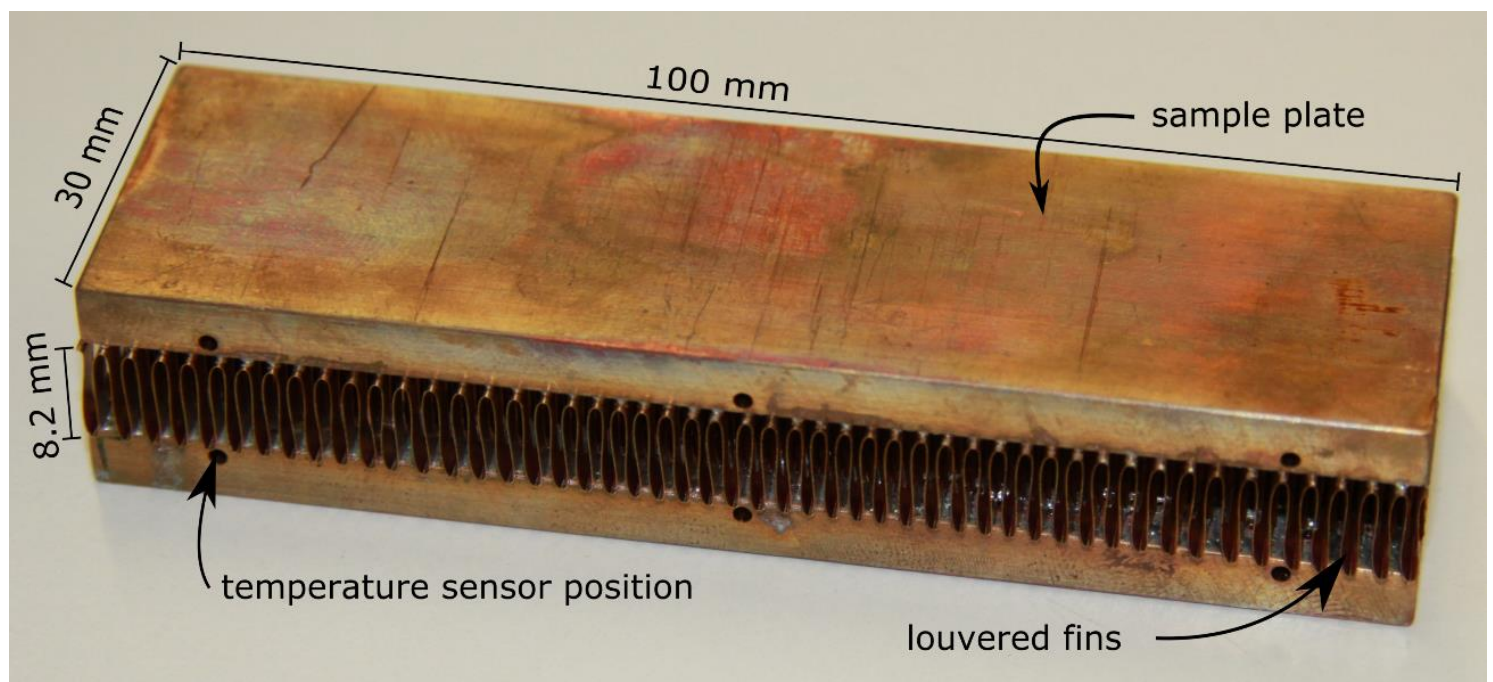

Figure 2. Louvered fin test core with top and bottom sample plate for experimental performance analysis. 
Table 2. Morphological parameters for the test samples.

\begin{tabular}{|c|c|c|c|c|}
\hline & Unit & Parameter & Wire Structure & Louvered Fin \\
\hline wire diameter/fin thickness & $\mathrm{mm}$ & $d_{\text {wire }} / d_{\text {fin }}$ & 0.25 & 0.04 \\
\hline channel height & $\mathrm{mm}$ & $H_{\text {channel }}$ & 10 & 8.15 \\
\hline sample length & $\mathrm{mm}$ & $L_{\text {st }}$ & 10 & 32 \\
\hline heat transfer surface area (inkl top and bottom sample plate) & $\mathrm{m}^{2}$ & $A_{\mathrm{HTS}}$ & 0.0198 & 0.058 \\
\hline volume of structure & $\mathrm{m}^{2}$ & $V_{\text {st }}$ & $1 \times 10^{-5}$ & $2.6 \times 10^{-5}$ \\
\hline material & - & - & Cu-ETP & $\mathrm{Cu}$-ETP \\
\hline thermal conductivity of wire/fin material & $\mathrm{W} / \mathrm{mK}$ & $k_{\mathrm{st}}$ & 385 & 385 \\
\hline mass specific surface area & $\mathrm{m}^{2} / \mathrm{kg}$ & - & 1.95 & 6.21 \\
\hline porosity & $\%$ & $\phi$ & 88.4 & 96.0 \\
\hline effective heat conductivity & $\mathrm{W} / \mathrm{mK}$ & $k_{\text {st,eff }}$ & 46.2 & 15.52 \\
\hline volume specific weight & $\mathrm{kg}^{2} / \mathrm{m}^{3}$ & $\begin{array}{l}n_{\text {st,eff }} \\
-\end{array}$ & 1009 & 361 \\
\hline volume specific surface area & $\mathrm{m}^{2} / \mathrm{m}^{3}$ & $\beta$ & 1970 & 2240 \\
\hline
\end{tabular}

\subsection{Micro Pin Fins}

A wire structure geometry was used as the second method of surface area enhancement in this study. Two idealized approaches for geometrical arrangement of the wires are common: The wires are arranged in-line or in a staggered manner as shown in Figure 3. The wires are separated by $l_{\text {long }}$ in the air flow direction and by $l_{\text {lat }}$ in the direction perpendicular to the air flow. In this study the sample wire structure is in a staggered arrangement. The manufacturing of the sample consists of (i) cutting of the copper wires to equal length; (ii) forming a wire bundle; (iii) positioning of the wires on a perforated metal plate; (iv) soldering of the wires to the bottom sample plate, and (v) soldering the wires to the top sample plate. The test core (Figure 4) has geometrical irregularities due to this manual manufacturing process. Mean morphological properties are given in Table 2. The test core was design, such that thermo-hydraulic performance for velocities of 2 to $2.5 \mathrm{~m} / \mathrm{s}$ could be determined.

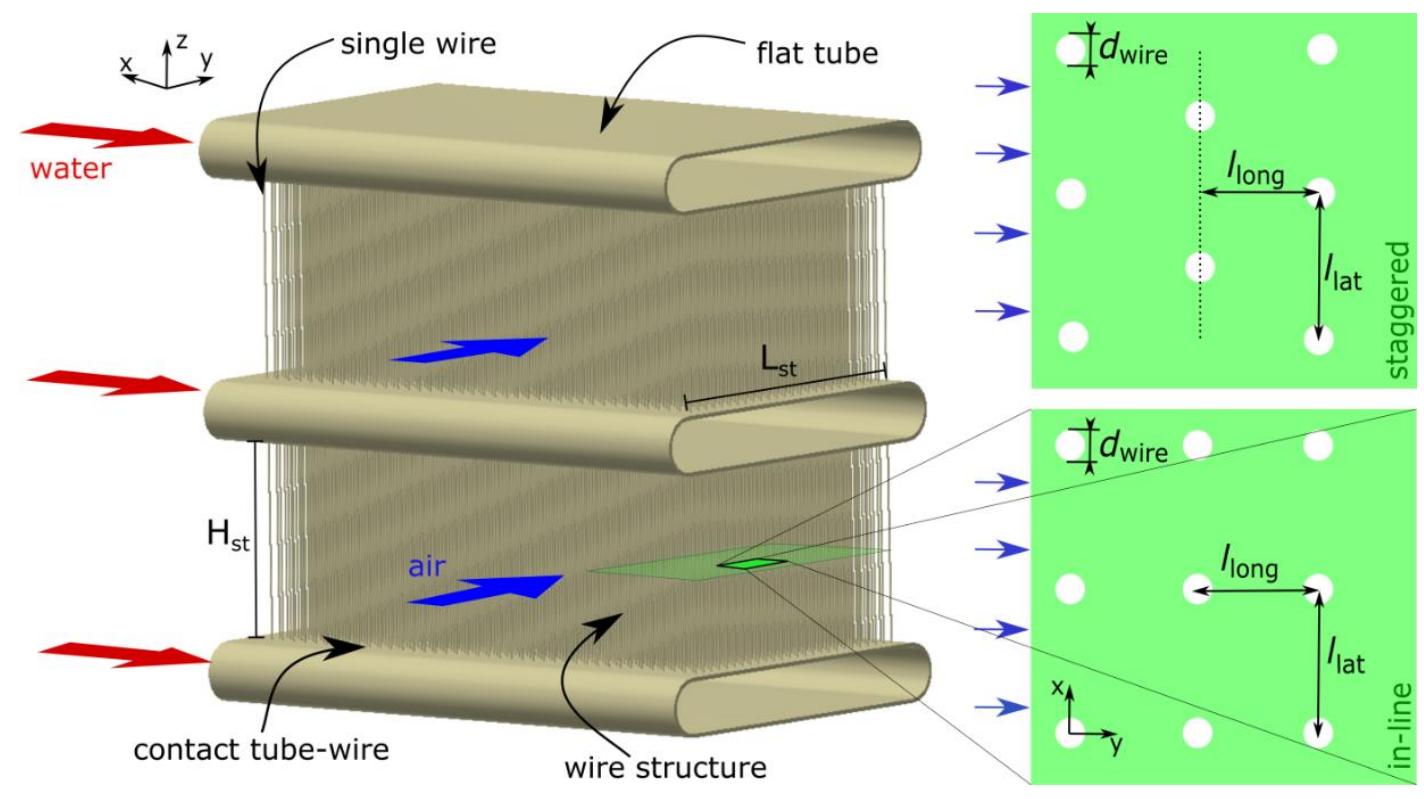

Figure 3. Section of an idealized wire structure heat exchanger with parallel wires between two separating plates; possible design with pin fins and flat tubes (left); Arrangement of wires (right). 


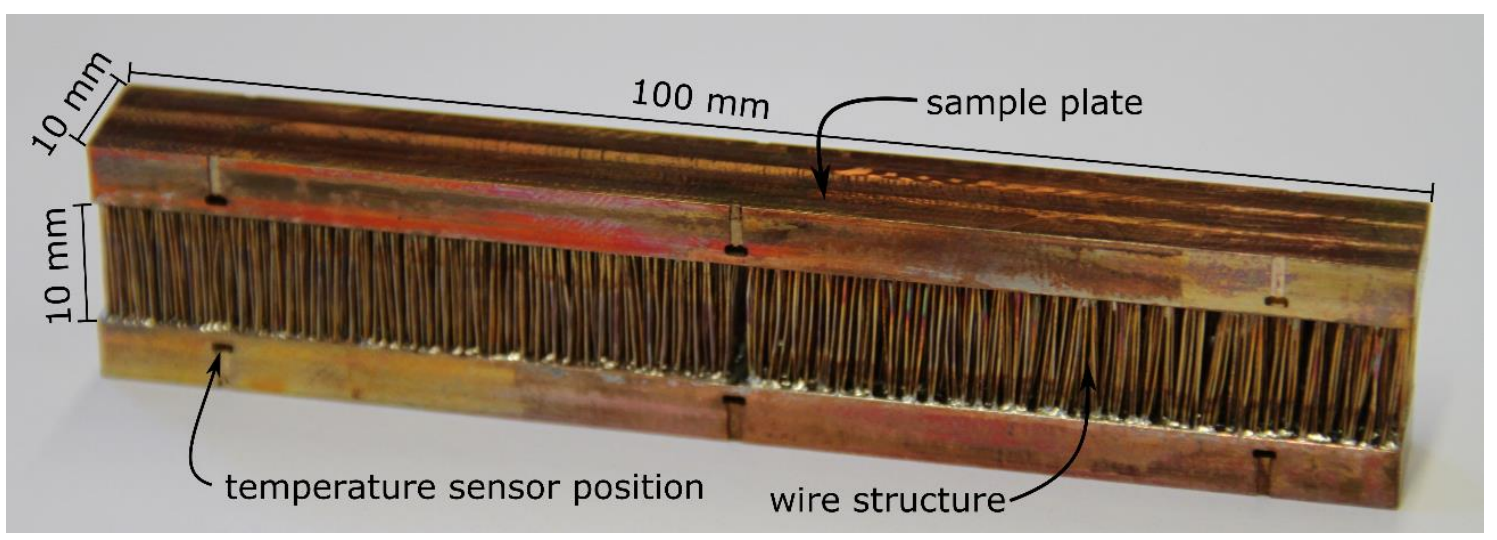

Figure 4. Micro pin fin test core with 2296 parallel copper wires (diameter $250 \mu \mathrm{m}$ ) soldered to bottom and top copper plates for experimental performance analysis.

\section{Experimental Setup}

\subsection{Test Set-Up}

A schematic diagram of the test rig for pressure drop and heat transfer measurements is shown in Figure 5. The main components are: air flow conditioning section, test section, test sample, test core, and data acquisition.

The air flow conditioning section is installed prior to the test section. It comprises a chiller, an electric heater, a humidifier, a controllable fan and the respective sensors for air temperature, humidity and volume flow (orifice plate). It can deliver temperatures in the range of -10 to $40{ }^{\circ} \mathrm{C}$ and volume flow rates between $80 \mathrm{~m}^{3} / \mathrm{h}$ and $300 \mathrm{~m}^{3} / \mathrm{h}$. Preconditioned air, as coolant, is drawn from the conditioning section to the test section. A bypass can optionally be used for lower air velocities at the beginning of the test section. Air passes a humidity sensor (HMT120; Vaisala, Vantaa, Finland; standard uncertainty of $\pm 3 \%$ relative humidity) and thereafter a mass flow sensor. Two options are available for the mass flow sensor; Option 1 is suited for low flow rates up to $50 \mathrm{~L} / \mathrm{min}$ (Red-y; Vögtlin Instruments $\mathrm{GmbH}$, Aesch, Switzerland; standard uncertainty of $0.5 \%$ of measured value $+0.15 \mathrm{~L} / \mathrm{min}$ ); Option 2 is suited for flow rates from 50 to $190 \mathrm{~L} / \mathrm{min}$ (TA Di 16 GE; Höntzsch GmbH, Waiblingen-Hegnach, Germany; standard uncertainty of $2 \%$ of measured value $+0.24 \mathrm{~L} / \mathrm{min}$ ). The channel enlarges after the mass flow meter and before the test sample. The ratio of channel length to channel height for this section is $L_{\text {channel, in }} / H_{\text {channel }}=14$. The channel itself has a cross section of $10 \mathrm{~mm} \times 100 \mathrm{~mm}$.

Within the enclosure and before reaching the test sample, efforts were made to ensure the coolant flow velocity was constant (uniform) all over the cross section. To achieve this, the coolant first flows through a porous foam, then $10 \mathrm{~mm}$ and $5 \mathrm{~mm}$ before the sample core through a homogenizer grid based on a polyamide mesh with a mesh size of $0.5 \mathrm{~mm}$.

After the air passed the sample, two homogenizer grids were positioned $5 \mathrm{~mm}$ and $10 \mathrm{~mm}$ behind the sample to ensure uniform velocity for temperature measurement. Air passes a second humidity sensor (HMT120) and finally a fan (G1G126-AB13-13; ebm-papst, Mulfingen, Germany). The fan is installed to control the volume flow of air in more detail and to run preliminary without the air flow conditioning section.

For pressure drop measurements, a differential pressure sensor for a measurement range from 0 to $60 \mathrm{~Pa}$ (CXLdp; ICS Schneider, Neuendorf, Germany; standard uncertainty $0.54 \mathrm{~Pa}$ ) and for 50 to $250 \mathrm{~Pa}$ (Druckaufnehmer PI-Sensor; halstrup-walcher GmbH, Kirchzarten, Germany; standard uncertainty $2.8 \mathrm{~Pa}$ ) were positioned at the inlet and outlet of the test sample, respectively. The absolute pressure can be measured (331113; Feingeräte Fischer, Drebach, Germany; 90 to $105 \mathrm{kPa}$, standard uncertainty $0.1 \mathrm{kPa}$ ) at the beginning and end of the test section and $25 \mathrm{~mm}$ before the test sample. 

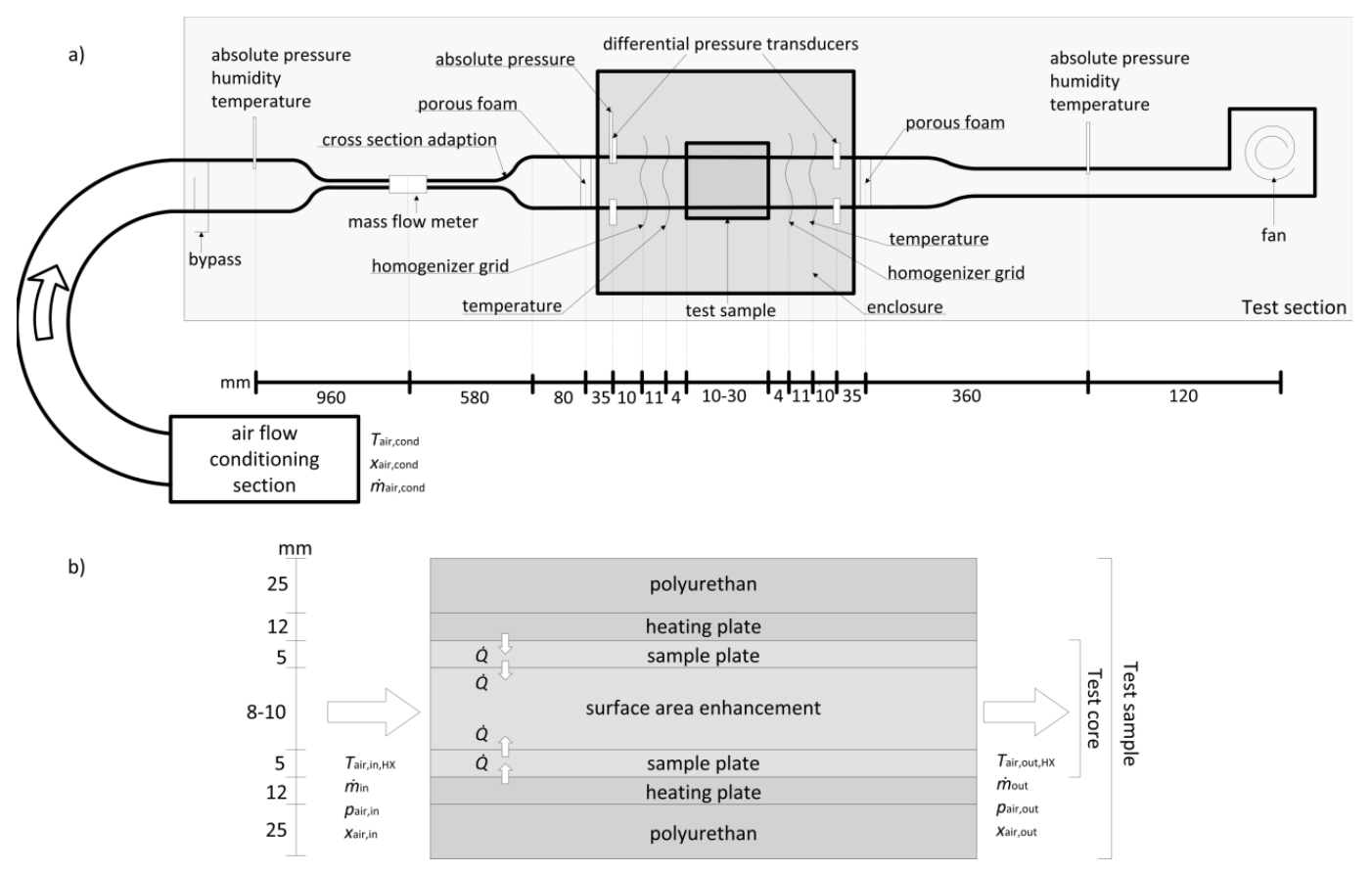

Figure 5. Experimental test set-up scheme: (a) forced air convection test section for small scale heat exchanger samples and (b) test sample with test core, heating plates and sensor information.

For heat transfer measurement, a constant wall temperature boundary condition was imposed on the bottom and top face of the test core by two heating cartridges $(24 \mathrm{~V} / 100 \mathrm{~W}, \varnothing 5 \mathrm{~mm} \times 100 \mathrm{~mm}$; Friedr. Freek $\mathrm{GmbH}$, Menden, Germany) installed in the heating plates.

A heat conducting foil (thermal pad $1 \mathrm{~mm} ; 3 \mathrm{M}$, Maplewood, MN, USA), was inserted between the heating plates and the sample plates to ensure the uniformity of the temperature. 12 thin PT-100 temperature sensors (RTD Platinum Sensor, IST AG, Ebnat-Kappel, Switzerland, calibrated standard uncertainty $0.1 \mathrm{~K}$ ) with $1.6 \mathrm{~mm} \times 1.2 \mathrm{~mm} \times 0.6 \mathrm{~mm}$ outer dimensions were mounted in the heating plates. 12 additional PT-100 temperature sensors were mounted in the sample plates (see Figures 2 and 4). Two self-built meandering platinum wire temperature sensors (each $0.5 \mathrm{~m}$ long, $0.025 \mathrm{~mm}$ diameter platinum wire, threaded in polyamide mesh, ca $100 \Omega$ at $0{ }^{\circ} \mathrm{C}$; calibrated standard uncertainty $0.1 \mathrm{~K}$ ) were positioned within the homogenizer grids at the inlet and outlet of the test sample to measure the coolant temperature at the cross section. Thus an integrative value for air temperature for the channel cross section can be determined. To minimize heat losses to the ambient a test sample enclosure was installed. It consists of a polyurethane box which is lined from the inside with the insulation material Styrodur ${ }^{\circledR}$. The test core and heating plate is closed at top and bottom by panels of polyurethane which are screwed together to hold the heating plate, test core, and the temperature sensors in position.

All measurements were performed under steady-state conditions and repeated until significant data repetition was ensured. The usual time to reach steady state was less than $10 \mathrm{~min}$; however, the boundary conditions have been kept constant for $30 \mathrm{~min}$. The measurements were taken at several different air velocities ranging from 0.25 to $4 \mathrm{~m} / \mathrm{s}$. The heating power was chosen, such that the maximum heating plate temperature was below $68^{\circ} \mathrm{C}$ to prevent deformation or melting of test section parts. Details of the test rig are given in Figure 6. 

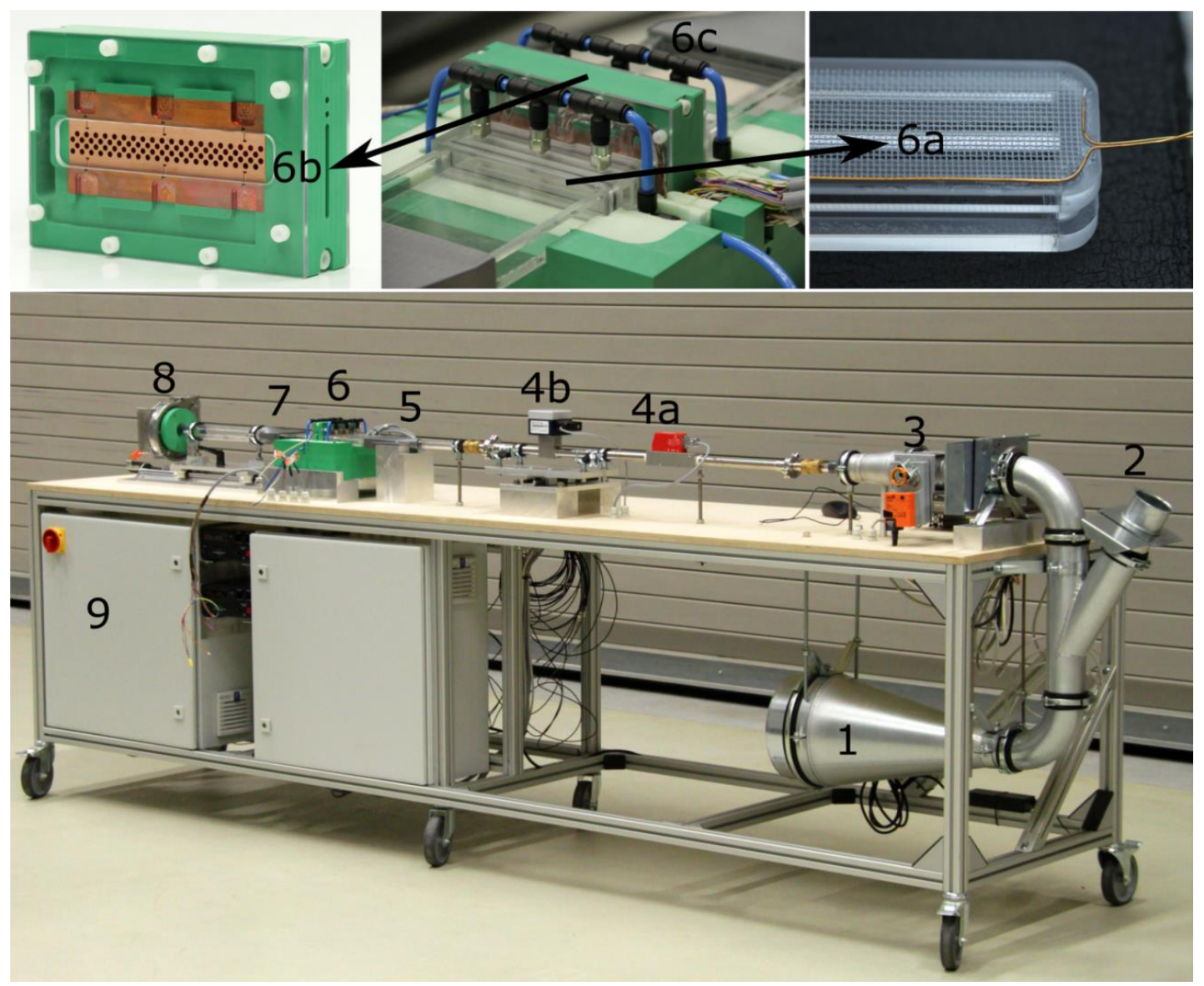

Figure 6. View of the test section and additional components; 1: preconditioned air inlet; 2: bypass; 3: throttle valve; $4 \mathrm{a}$ and b: mass flow rate sensors; 5 : cross section adaption; 6 : test sample enclosure; 6a: platinum wire temperature sensor threaded in polyamide mesh; 6b: test sample; 6c: differential pressure probes; 7: contraction duct; 8: fan; 9: electric cabinet.

\subsection{Data Reduction Parameters}

The total heat transfer rate in the heat exchanger:

$$
\dot{Q}_{\mathrm{HX}}=\dot{m}_{\mathrm{air}} c_{p, \text { air }} \Delta T_{\mathrm{air}, \mathrm{HX}}
$$

and the overall heat transfer $U_{\mathrm{HX}} A_{\mathrm{HTS}}$, defined as:

$$
U_{\mathrm{HX}} A_{\mathrm{HTS}}=\dot{Q} / \Delta T_{m}
$$

can be calculated based on the measurement data. Equations (1) and (2) are based on the mass flow rate $\dot{m}_{\text {air }}$, the specific heat $c_{p \text {,air }}$, the temperature difference $\Delta T_{\text {air, } \mathrm{HX}}$ of air inlet and outlet temperatures in the heat exchanger, and the true (or effective) mean temperature difference, also referred to as the mean temperature driving potential $\Delta T_{\mathrm{m}}$. The true mean temperature difference is defined as:

$$
\Delta T_{\mathrm{m}}=\frac{\left(T_{\text {air,in,HX}}-T_{\text {saplt,in }}\right)-\left(T_{\text {air,out,HX }}-T_{\text {saplt,out }}\right)}{\ln \left(\frac{T_{\text {air,in, }, \mathrm{HX}}-T_{\text {saplt,in }}}{T_{\text {air,out,HX}}-T_{\text {saplt,out }}}\right)},
$$

where the temperature $T_{\text {saplt,in }}$ and $T_{\text {saplt,out }}$ are the sample plate temperature. They are calculated for the inlet and outlet as a mean of the 6 sensor signals at the beginning and at the end of the sample 
plate, respectively (cf. sensor position in Figures 2 and 4). The temperatures $T_{\text {air,in,HX }}$ and $T_{\text {air,out,HX }}$ represent the air temperatures directly before and after the heat exchanger structure. They are based on the measurement with the self-built meandering sensors $\left(T_{\text {air,in }}\right.$ and $\left.T_{\text {air,out }}\right)$, but corrected due to gains and losses within the channel between the sensor and the test core. The corrections at the inlet and outlet are below $0.3{ }^{\circ} \mathrm{C}$ and $0.02{ }^{\circ} \mathrm{C}$, respectively for the enhancements tested in this study.

The product of the heat transfer surface area $A_{\mathrm{HTS}}$ on the air side (including the enhancement structure and the sample plate surface area in contact with air; $A_{\mathrm{HTS}}=A_{\mathrm{HTS}, \mathrm{st}}+A_{\mathrm{HTS}, \mathrm{p}}$ ) and the overall heat transfer coefficient $U_{\mathrm{HX}}$ can be separated into its factors, if the heat transfer surface area is known.

When a (pin fin) wire structure is contacted to a heating plate, the same procedure as for conventional fins can be applied to estimate the airside convective heat transfer coefficient. For the

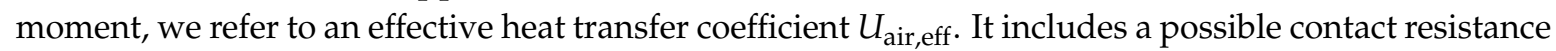
between fins and wall, the heat conduction through the fins, and the convective heat transfer from the fins and the sample wall to the air; but not the heat transfer from the heating plate to the sample plate $[3,19]$. The effective heat transfer coefficient $U_{\text {air,eff }}$ refers to the same heat transfer surface area $A_{\mathrm{HTS}}$ as $U_{\mathrm{HX}}$ described in Equation (2). For the experiments, the air side wall temperature $T_{\text {wall,air }}$ is not known, so $U_{\text {air,eff }}$ has to be determined indirectly from the overall heat transfer $U_{\mathrm{HX}} A_{\mathrm{HTS}}$. The latter is the result of a series connection of $U_{\text {air,eff }} A_{\mathrm{HTS}}$ and the conduction through the sample plate. Thus:

$$
\frac{1}{U_{\text {air,eff }} A_{\mathrm{HTS}}}=\frac{1}{U_{\mathrm{HX}} A_{\mathrm{HTS}}}-\frac{\delta_{\text {saplt }, \mathrm{T}}}{k_{\text {saplt }} A_{\text {saplt }}}
$$

holds. The cross sectional surface area of the wall $A_{\text {saplt }}$ is the same as the heating plate surface area. The parameter $\delta_{\mathrm{saplt}, \mathrm{T}}$ is the thickness of the sample plate from the temperature measurement position to the wall in contact with air.

The pressure drop $\Delta p_{\text {air }}$ is based on the differential pressure sensor. For measurement of differential pressure the homogenizer grids and temperature sensors in the channel before and after the test core have been taken out.

The Nusselt number on the air side is a non-dimensional quantity, expressing the convective heat transfer versus the conductive heat transfer. It is defined as:

$$
\mathrm{Nu}_{\mathrm{air}}=\frac{h_{\mathrm{air}} d_{\mathrm{ch}}}{k_{\mathrm{air}}}
$$

where $d_{\mathrm{ch}}$ is a characteristic length of the air side of the heat exchanger which is chosen in this study to be the wire diameter of $0.25 \mathrm{~mm}$. An equal characteristic length for all heat exchangers allows for easy comparison of different kinds of fins in terms of Reynolds number and Nusselt number. Thus the characteristic length is taken to be $0.25 \mathrm{~mm}$ for the louvered fin as well. The convective heat transfer coefficient on the air side $h_{\text {air }}$ can only be determined if the conductive heat resistance of the sample plate and the fins is known. This is in general not possible by means of a measurement but by means of a simulation/calculation. Therefore the Nusselt number $\mathrm{Nu}_{\text {air }}$ can be presented for CFD-simulated heat exchangers or very well defined geometry with an available formula for fin efficiency only. The later condition holds for the pin fins and louvered fins. The heat transfer coefficient $h_{\text {air }}$ and effective heat transfer coefficient $U_{\text {air,eff }}$ can then be related via the extended surface efficiency $\eta_{0}[20]$, determined from fin efficiency of pin fins and louvered fins (see Appendix A) by:

$$
U_{\text {air,eff }}=\eta_{0} h_{\text {air }} .
$$

The non-dimensional representation of pressure drop is the Fanning friction factor $f_{\text {air }}$ which is given by:

$$
f_{\text {air }}=\frac{\Delta p_{\text {air }}}{4\left(\frac{L_{\text {st }}}{d_{\text {ch }}}\right)\left(\frac{\rho_{\text {air }} v_{\text {air }}^{2}}{2}\right)}
$$


with $v_{\text {air }}$ representing the mean velocity on the air side of the heat exchanger structure and $L_{\text {st }}$ being the length of heat exchanger structure in air flow direction. The non-dimensional quantities can be related to the airside Reynolds number:

$$
\operatorname{Re}_{\mathrm{air}}=\frac{\rho_{\mathrm{air}} v_{\mathrm{air}} d_{\mathrm{ch}}}{\mu_{\mathrm{air}}}
$$

with air side dynamic viscosity $\mu_{\text {air }}$. Additional information on the heat transfer process can be expressed with the air side effectiveness:

$$
\epsilon_{\text {air }}=\frac{\Delta T_{\text {air, } \mathrm{HX}}}{\Delta T_{\max }}=\frac{T_{\text {air,in, } \mathrm{HX}}-T_{\text {air,out }, \mathrm{HX}}}{T_{\text {air, }, \mathrm{in}, \mathrm{HX}}-T_{\text {saplt,out }}} .
$$

\subsection{Uncertainty Analysis}

The uncertainties of the temperature sensors given in Section 3.1 are one part of the uncertainty in the test set-up to determine sample plate and air inlet/outlet temperatures. The positioning and number of sensors can influence the uncertainty as well. As the sample plate temperature is a mean value, based on several temperature sensors, a standard deviation can be calculated. This deviation expresses the scattering of temperature within the sample plate around the mean. A large deviation restricts the method of logarithmic mean temperature difference (Equation (3)) as the local difference between air outlet temperature and sample plate temperature might differ from the mean difference. Thus in some areas of the heat exchanger the driving temperature difference (between sample plate and air) might be very low, whereas in other parts it might still be large. As the logarithmic mean temperature is strongly non-linear a mean value will not express the correct driving temperature. Therefore an additional uncertainty of the mean sample plate temperature has been added to the uncertainty analysis. Figure 7 shows the mean values and the standard deviation of the sample plate temperature of the wire structure. The standard deviation of the temperature values varies from $0.6 \mathrm{~K}$ to $1.7 \mathrm{~K}$. The standard deviation of the temperature mean is by a factor of $1 / \sqrt{6}$ smaller, due to the number of sensors. It will be used as uncertainty for the sample plate mean temperature.

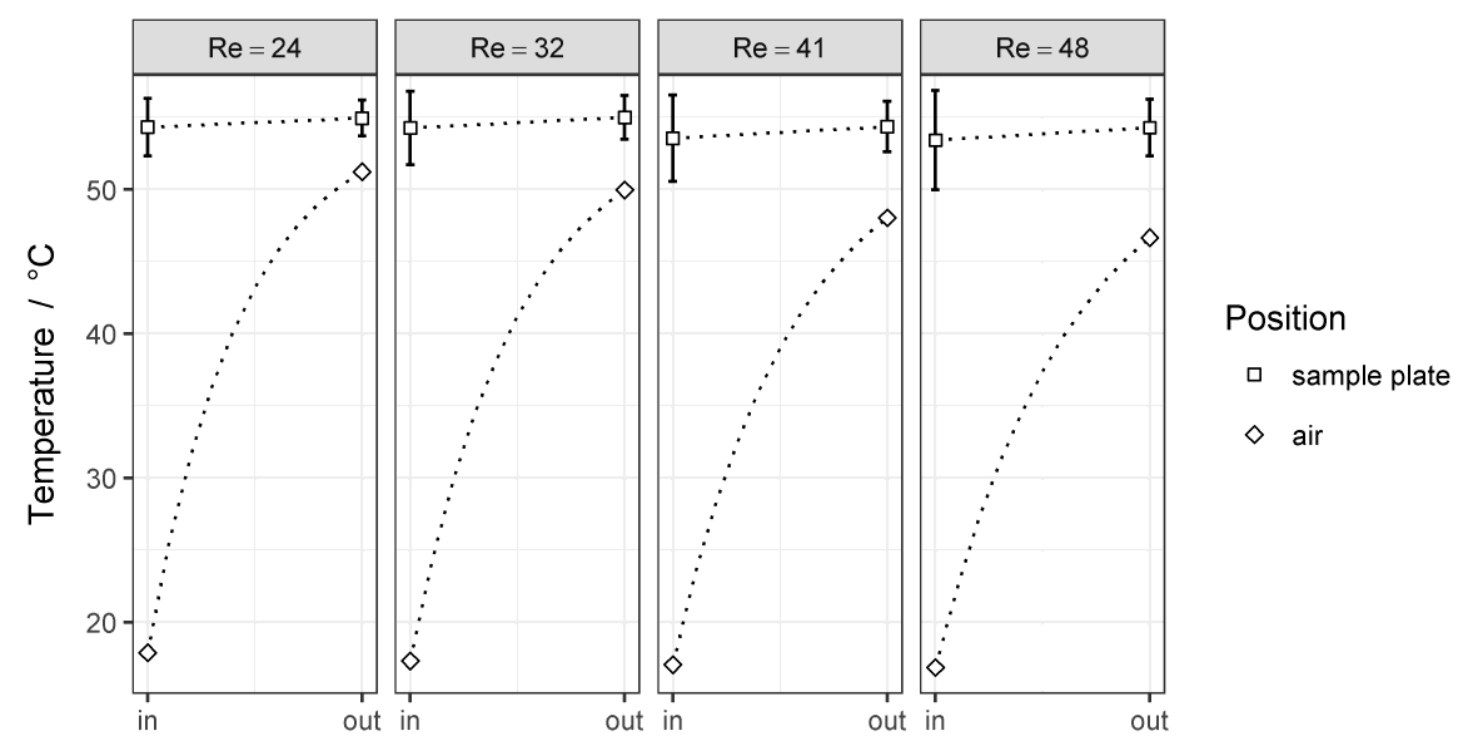

Figure 7. Mean inlet and outlet temperatures of the air and sample plate with respect to different Reynolds numbers $\operatorname{Re}_{a i r, s t}$ for the wire structure. Twice the standard deviation of the measured temperature value is given for the sample plates as error bars, representing $95 \%$ of the data. 
The air inlet and outlet temperatures used in Equations (1) and (3) are integrative values. Exemplarily the definition of $T_{\text {air, in }}$ is given by:

$$
T_{\text {air,in }}=\frac{\int_{A_{\text {stin }}} v_{\text {air }} \rho_{\text {air }} c_{p, \text { air }} T_{\text {air }}}{\int_{A_{\text {st,in }}} v_{\text {air }} \rho_{\text {air }} c_{p, \text { air }}} .
$$

However, the temperature sensor in the air flow measures the temperature:

$$
T_{\text {air,in,meas }}=\int_{A_{\text {st,in }}} T_{\text {air }} \text {. }
$$

Both temperatures are equal if the velocity $v_{\text {air }}$, the density $\rho_{\text {air }}$ and the heat capacity $c_{p \text {,air }}$ are constant within the air inlet cross section $A_{\text {st,in }}$. This assumption holds for well mixed air flow. In the present test section this is realized by several grids in front of the temperature sensors. However, CFD simulations of the homogenizer grids and air flow through the channel show that a strongly uniform flow cannot be reached. Related to the operating conditions an additional uncertainty of $0.26 \mathrm{~K}$ and $0.09 \mathrm{~K}$ has been assigned to the air inlet and outlet temperature, respectively.

Lastly the pressure drop measurement has additional uncertainty due to the position of the sensors in the channel. However CFD simulations of the channel air flow show a very low deviation of maximum/minimum pressure in the channel cross section compared to the mean pressure, such that the sensor uncertainty determines the uncertainty. No additional uncertainty has been added.

Table 3 shows the sensor uncertainties and the additional uncertainties related to position and averaging. The uncertainty of the experimental results is assessed based on measurement uncertainties using the Gaussian uncertainty propagation rule [21]. The level of confidence is expressed in terms of an expanded uncertainty interval. The expanded uncertainty is obtained by multiplying the combined standard uncertainty by a coverage factor of 2 . Assuming that the measurement data are normally distributed, $95 \%$ of the data lies in this interval.

Table 3. Uncertainties of main parameters for pin fin test sample; sensor uncertainties are based on manufacturer information or calibration; additional uncertainties are related to positioning and averaging.

\begin{tabular}{lcccc}
\hline & Dimension & $\begin{array}{c}\text { Sensor Uncertainty } \\
\boldsymbol{u}_{\mathbf{1}} \text { (Rectangular Distr) }\end{array}$ & $\begin{array}{c}\text { Additional Uncertainty } \\
\boldsymbol{u}_{\mathbf{2}} \text { (Normal Distr.) }\end{array}$ & $\begin{array}{c}\text { Combined Uncertainty } \\
\sqrt{\left(\frac{\boldsymbol{u}_{\mathbf{1}}}{\sqrt{3}}\right)^{\mathbf{2}}+\left(\boldsymbol{u}_{\mathbf{2}}\right)^{\mathbf{2}}}\end{array}$ \\
\hline$T_{\text {air,in }}$ & $\mathrm{K}$ & 0.1 & 0.26 & 0.27 \\
$T_{\text {air,out }}$ & $\mathrm{K}$ & 0.1 & 0.09 & 0.11 \\
$T_{\text {saplt,in }}$ & $\mathrm{K}$ & 0.1 & $0.41-0.70$ & $0.41-0.70$ \\
$T_{\text {saplt,out }}$ & $\mathrm{K}$ & 0.1 & $0.25-0.40$ & $0.26-0-40$ \\
$\Delta p_{\text {air }}$ & $\mathrm{Pa}$ & $0.54-2.8$ & 0 & $0.31-1.62$ \\
$\dot{m}_{\text {air }}$ & $10^{-5} \mathrm{~kg} / \mathrm{s}$ & $4.0-7.7$ & 0 & $2.4-4.4$ \\
\hline
\end{tabular}

\section{Performance Evaluation}

Several different velocities have been measured with a focus on velocities through the structure in the range of 2 to $2.5 \mathrm{~m} / \mathrm{s}$. The heat flow rates ranged from $30 \mathrm{~W}$ to $110 \mathrm{~W}$, dependent on the velocity and enhancement structure (see Figure 8). As the pin fin test core had a 20\% higher channel height, compared to the louvered fins, the air mass flow rate at equal velocities differ. Thus, it was possible to have higher heat flow rates for the pin fins at equal velocities. High heat flow rates are not necessarily related to high thermal performance, but are a consequence of geometric and operational conditions, which differ between pin fin and louvered fin enhancement. 


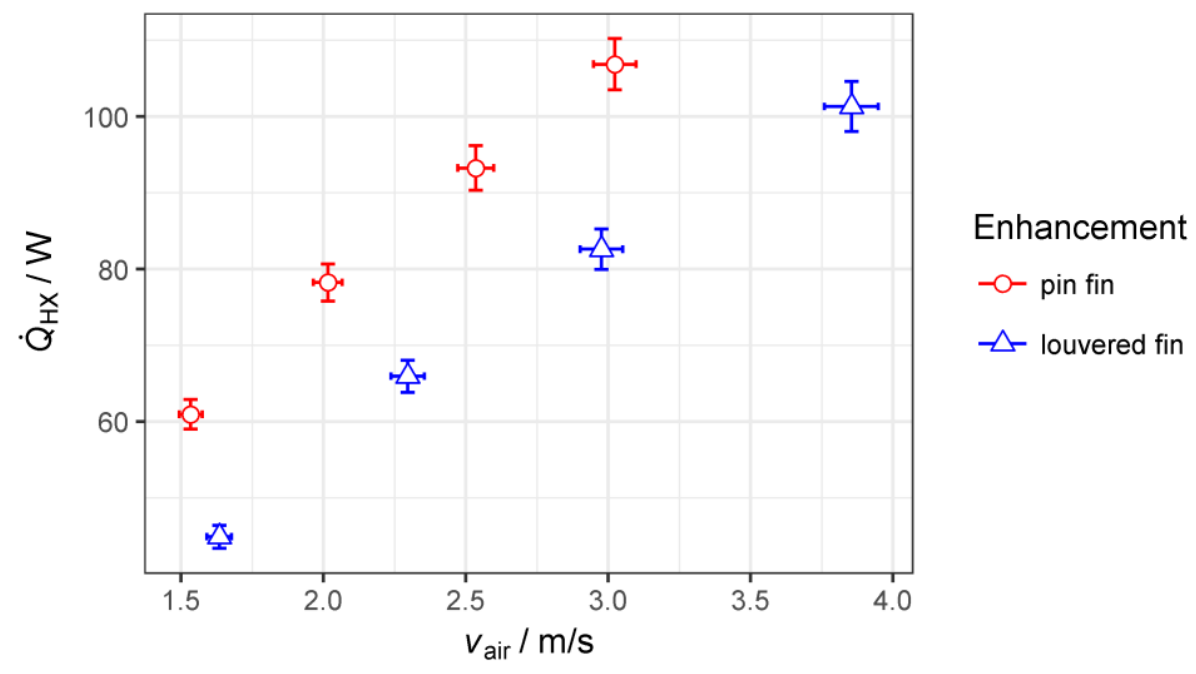

Figure 8. Heat flow rate $\dot{Q}_{\mathrm{HX}}$ versus air velocity $v_{\text {air }}$ for louvered and pin fins; error bars for expanded uncertainty.

The air flow at the outlet reached temperatures close to the sample plate temperature for low velocities. Thus the uncertainty of the thermal performance key figures is high for those values. An overview of the experimentally determined data points is given in Table 4. The air side effectiveness $\epsilon_{\text {air }}$ can be considered within the table. With increasing velocity the effectiveness decreases due to a higher increase of the capacity flow rate $\dot{m} c_{p}$ compared to the increase of the effective heat transfer coefficient $U_{\text {air,eff. }}$ Thus measurements of thermal performance at lower velocities than the depicted could not be performed, as the uncertainty increased too strong. The energy balances between the heat flow rate into the heat exchanger structure and air $\dot{Q}_{\mathrm{HX}}$ and the electric power $P_{\mathrm{el}}$ matches with a relative difference of maximum $4 \%$.

Table 4. Selection of experimentally determined data points for thermal performance evaluation.

\begin{tabular}{|c|c|c|c|c|c|c|c|c|c|c|}
\hline & \multicolumn{3}{|c|}{ Input } & \multicolumn{6}{|c|}{ Output } & \multirow[b]{2}{*}{$\begin{array}{l}\eta_{0} \\
{[-]}\end{array}$} \\
\hline & $\begin{array}{c}T_{\text {air,in }} \\
{[\mathrm{K}]}\end{array}$ & $\begin{array}{c}v_{\text {air }} \\
{[\mathrm{m} / \mathrm{s}]}\end{array}$ & $\begin{array}{c}P_{\mathrm{el}} \\
{[\mathrm{W}]}\end{array}$ & $\begin{array}{l}\dot{Q}_{\mathrm{HX}} \\
{[W]}\end{array}$ & $\begin{array}{c}T_{\text {saplt,in }} \\
\text { [K] }\end{array}$ & $\begin{array}{c}T_{\text {saplt,out }} \\
{[\mathrm{K}]}\end{array}$ & $\begin{array}{c}T_{\text {air,out }} \\
{[\mathrm{K}]}\end{array}$ & $\begin{array}{c}\epsilon_{\text {air }} \\
{[-]}\end{array}$ & $\begin{array}{l}U_{\text {air,eff }} \\
{\left[\mathrm{W} / \mathbf{m}^{2} \mathbf{K}\right]}\end{array}$ & \\
\hline \multirow{4}{*}{ micro pin fin } & 17.9 & 1.6 & 60 & 61 & 54.3 & 54.9 & 51.2 & 0.90 & 217.1 & 0.93 \\
\hline & 17.3 & 2.1 & 76 & 78 & 54.3 & 55.0 & 50.0 & 0.86 & 249.8 & 0.92 \\
\hline & 17.1 & 2.7 & 90 & 93 & 53.5 & 54.3 & 48.0 & 0.83 & 277.2 & 0.91 \\
\hline & 16.9 & 3.2 & 104 & 107 & 53.4 & 54.3 & 46.7 & 0.79 & 296.1 & 0.91 \\
\hline \multirow{4}{*}{ louvered fin } & 21.2 & 1.7 & 47 & 45 & 49.0 & 50.2 & 49.6 & 0.98 & 109.5 & 0.92 \\
\hline & 21.2 & 2.4 & 67 & 66 & 50.8 & 52.3 & 51.0 & 0.96 & 125.9 & 0.91 \\
\hline & 21.6 & 3.1 & 83 & 83 & 50.9 & 52.5 & 50.4 & 0.93 & 137.4 & 0.91 \\
\hline & 21.5 & 4.0 & 104 & 101 & 50.1 & 51.8 & 48.8 & 0.90 & 153.5 & 0.90 \\
\hline
\end{tabular}

The effective heat transfer coefficient for both enhancements is shown in Figure 9. The pin fin enhancement has more than twice the heat transfer coefficient for the considered velocity range of $1.5 \mathrm{~m} / \mathrm{s}$ to $3 \mathrm{~m} / \mathrm{s}$. Both enhancements show lower values of heat transfer coefficient for low air velocities. 


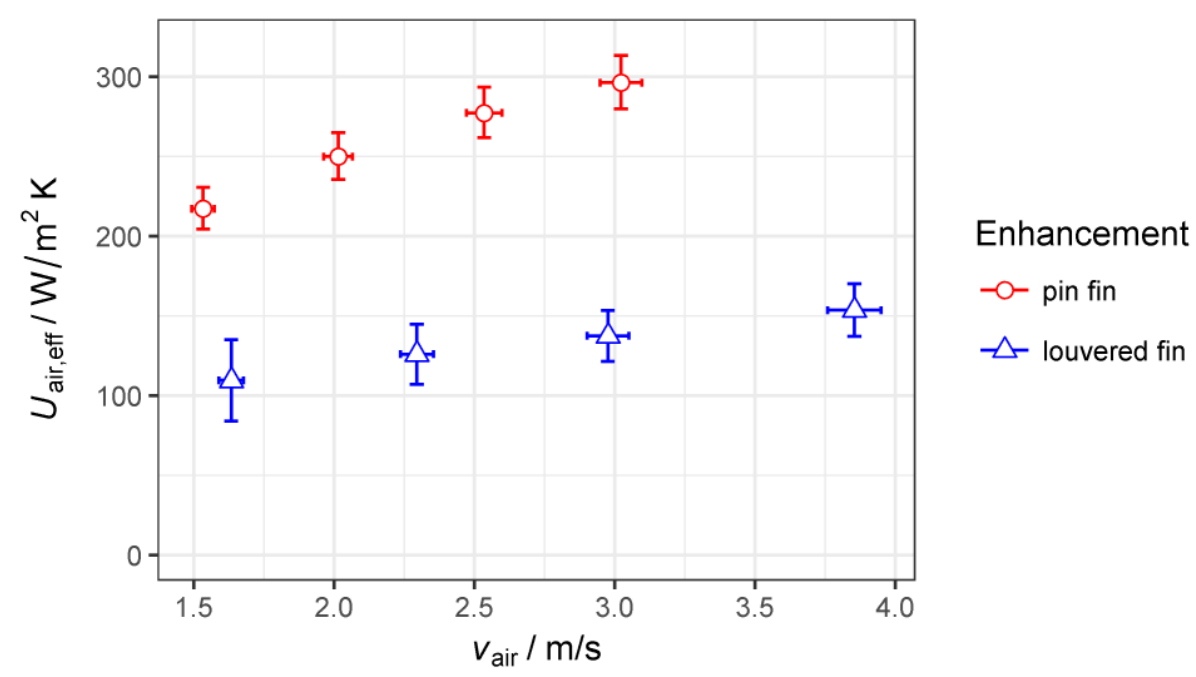

Figure 9. Effective heat transfer coefficient $U_{\text {air,eff }}$ versus air velocity $v_{\text {air }}$ for louvered and pin fins; error bars for expanded uncertainty.

The pressure drop measurements could be extended to lower velocities, thus Figure 10 shows the pressure drop per length of structure for velocities from $0.25 \mathrm{~m} / \mathrm{s}$ to $3.25 \mathrm{~m} / \mathrm{s}$. Pressure drop increases with respect to air velocity. The pressure drop of the pin fins is approximately twice as high as the pressure drop of the louvered fins.

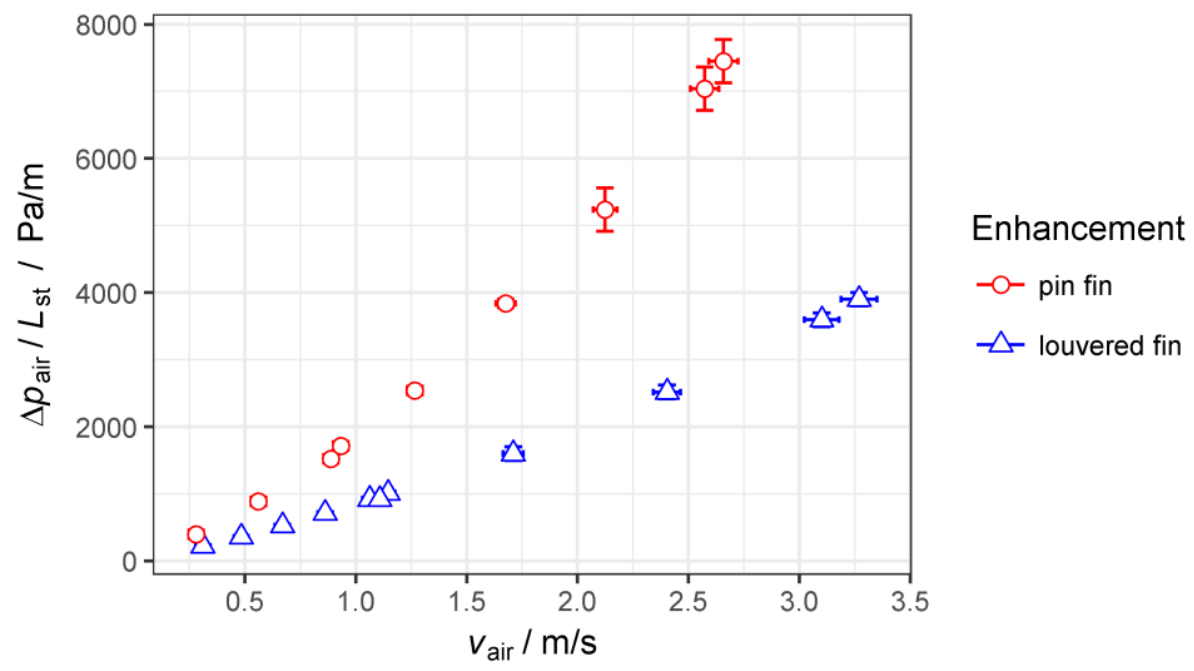

Figure 10. Pressure drop $\Delta p_{\text {air }}$ normalized with length of structure $L_{\text {st }}$ versus air velocity $v_{\text {air }}$ for louvered and pin fins; error bars for expanded uncertainty.

The experimental data for thermo-hydraulic performance is shown in non-dimensional form in Figure 11. The plots are extended with performance information from correlation in literature. The pin fins are correlated based on a 2D-CFD simulation [22], the louvered fins are correlated versus data from an experimental study [23].

The present measurement and the literature correlation for the louvered fins show a similar slope; the measurements show slightly higher Nusselt numbers and slightly lower Fanning friction factors.

The present measurement and the correlation for the pin fins show a different behavior. Whereas the 2D-CFD simulation data of the Nusselt number shows a slope comparable to the louvered fins, the measurement data shows a considerably steeper slope; the measurements show lower Nusselt 
numbers for low velocities and agree with the simulations for higher velocities. The measured Fanning friction factor for the pin fins shows a flatter slope compared to the simulations. A good agreement of friction factor can be found for lower velocities, for higher velocities the relative difference is in the order of $40 \%$.
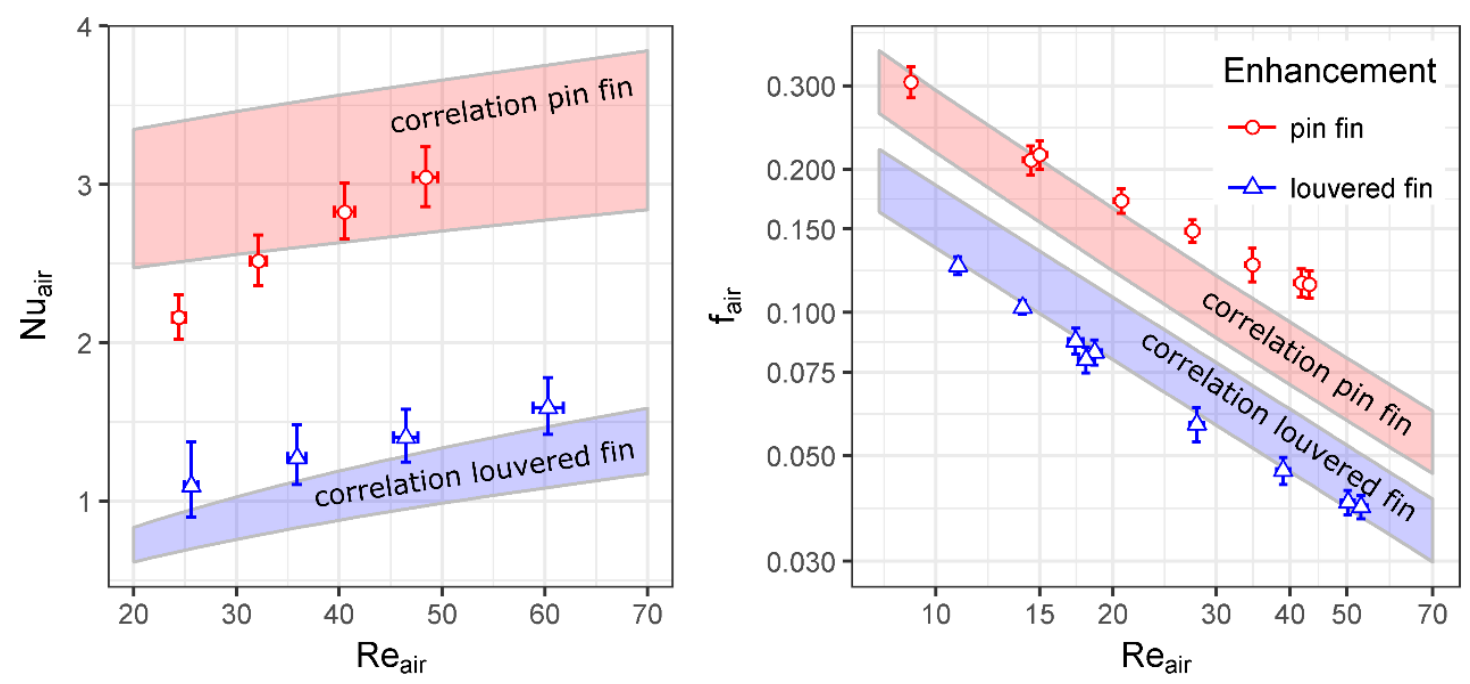

Figure 11. Thermo-hydraulic performance in non-dimensional form; Nusselt number $\mathrm{Nu}_{\mathrm{st}}(\mathbf{l e f t})$ and Fanning friction factor $\mathrm{f}_{\mathrm{st}}$ (right) versus Reynolds number $\mathrm{Re}_{\mathrm{st}}$; Ribbons represent correlated data for pin fins [22] and louvered fins [23]; error bars for expanded uncertainty.

Similar to Figures 9 and 10, the pin fin structure shows a clear enlargement of Nusselt numbers, with the drawback of a distinct enlargement of the friction factors.

\section{Discussion}

The test facility allows measurement of heat transfer and pressure drop characteristics for small scale heat exchanger test samples. The test facility can be operated at a variety of different air velocities. The operational conditions yield different uncertainties. The relative expanded uncertainty of the Nusselt number of the pin fins can be kept lower than $7 \%$ for Reynolds numbers between 25 and 50 . Data for lower Reynolds numbers show the common phenomenon of a strongly decreasing Nusselt number. A reason for this can be the very small temperature differences of the air outlet and the sample plate temperatures. These mean temperature differences are below $4{ }^{\circ} \mathrm{C}$ for velocities lower than $2 \mathrm{~m} / \mathrm{s}$. Furthermore, the sample plate temperature at the inlet and outlet differs for the 6 measurement points by $4.5^{\circ} \mathrm{C}$ and $3{ }^{\circ} \mathrm{C}$, respectively. Thus a constant homogenous heat flux cannot be guaranteed. Data for Reynolds numbers below 30 must be looked at carefully.

Similarly, the high uncertainties for the Nusselt number of the louvered fins can be explained. The very high value of effectiveness $\epsilon_{\text {air }}=0.98$ for low air velocities comes along with a small difference of air outlet and sample outlet temperature $(0.6 \mathrm{~K})$. Therefore, the expanded uncertainties in Nusselt number range from $12 \%$ to $26 \%$. The selection of this louvered fin geometry as a reference geometry was based on available and manufactural fins. A shortening of the fin length in air flow length could have been done to decrease the effectiveness and thus the uncertainty. However uncertainties in fin geometry might have increased the uncertainty again.

The relative expanded uncertainties for pressure drop and thus the relative expanded uncertainties for Fanning friction factor are for all Reynolds numbers $\left(6<\operatorname{Re}_{\text {st }}<52\right)$ and both fin types below $8 \%$. The necessity to differ between low pressure drops in the range of 5 to $50 \mathrm{~Pa}$ and pressure drops in the range of 50 to $250 \mathrm{~Pa}$ have proven to be true. The measured pressure drops range from 5 to $90 \mathrm{~Pa}$. The application of two sensors can be recommended, if the range of velocities shall be large. 
The measurement of air inlet and outlet temperature with a meandering platinum wire sensor is an unconventional approach for temperature measurement. It allows (i) an integrative measurement of the air temperature in the flow cross section; (ii) a small interference in fluid flow; (iii) a measurement close to the sample with the drawback of (iv) the necessity of equal velocities in the cross section of the sensor; (v) difficulties in the calibration of the senor due to a non-punctual measurement; and (vi) a very time consuming process of threading the platinum wire in the plastic mesh. If integrative measurements are needed the authors recommend to check for manufacturing possibilities of meandering platinum wire sensor.

The louvered fins show the thermo-hydraulic performance expected for the specific geometry based on literature data in [23]. The effective heat transfer coefficients are in the range of $100 \mathrm{~W} /\left(\mathrm{m}^{2} \mathrm{~K}\right)$ to $150 \mathrm{~W} /\left(\mathrm{m}^{2} \mathrm{~K}\right)$. In combination with the high volume specific surface area of $2240 \mathrm{~m}^{2} / \mathrm{m}^{3}$ and relatively low pressure drops of 2000 to $2800 \mathrm{~Pa} / \mathrm{m}$ (for 2-2.5 m/s) the enhancement shows very high performance. Despite the high uncertainties in measurements the Nusselt number follows the shape of curve from literature data.

The micro pin fin wire structure shows a slightly less promising thermo-hydraulic performance compared to the 2D-CFD simulations in [22]. There are several possible explanations for this result. First, the 2D simulation neglects influences of the sample plate wall; especially at high inlet velocities the shear stress at the wall influences the pressure, the velocity, and the temperature field. 3D-CFD simulations (non-published) show a 30\% higher Fanning friction factor for a Reynolds number of $\operatorname{Re}_{\mathrm{st}}=70$ for the pin fins compared to the 2D simulation. Second, the pin fin test core (Figure 4 ) has geometrical irregularities due to the manual manufacturing process. As a result, some wires are not contacted, not homogeneously distributed, and there are solder meniscuses on the soldering joints of the wires. A reduction in thermo-hydraulic performance is possible. The large differences in the sample plate temperature provide a first evidence of non-homogeneity.

In essence, the effective heat transfer coefficients are twice as high compared to the louvered fins and volume specific surface area is in similar dimension with $1970 \mathrm{~m}^{2} / \mathrm{m}^{3}$. The pressure drop shows significant increase compared to the louvered fins in the order of 2 . Thus the micro pins fins in a heat exchanger might fail to increase heat transfer significantly with use of less or equal fan power. Nevertheless the pin fins allow a reduction of the heat exchanger size in the order of 2 and thus allow new degrees of freedom in design and a significant material reduction. Furthermore, the tested pin fin wire structures have a wire diameter of $250 \mu \mathrm{m}$. A reduction to $100 \mu \mathrm{m}$ or less might be possible. Heat transfer coefficients can thus be increased further. Moreover, an in-line array of wires instead of the staggered wire structures (cf. [22]) could allow a strong decrease in pressure drop, with small losses in thermal performance.

The manufacturing of the pin fin structure is a continuation of the work from Sahiti [13] and Fugmann et al. [14], showing the preparation feasibility of thin pin fin heat exchangers with a wire diameter of $250 \mu \mathrm{m}$. For the first time a thermo-hydraulic performance measurement with well-defined boundary conditions could be realized. The development of the test rig is based on test facilities from various authors (see Table 1). An improvement is given by the possibility to measure very compact structures with small $(<1 \mathrm{~cm})$ lengths in flow direction. The uncertainties of performance parameters (e.g., Nusselt number) are in the same range as in the current state literature. The uncertainty analysis has been described explicitly in Section 3.3. In addition, the test facility can be used to measure the de- and adsorption of water on a coated sample due to the adjustment of air inlet humidity and temperature with the air flow conditioning section.

\section{Conclusions}

- A test facility for thermo-hydraulic performance measurements of small scale heat transfer surface area enhancements has been constructed.

- A performance comparison of different heat exchanger structures can be realized with less manufacturing costs than in standard tests. 
- An innovative micro pin fin structure and a louvered fin reference structure have been evaluated; other types of enhancement, such as foams, are suitable for measurement as well.

- The geometrical inaccuracy, the deformation of wire arrays, improper wire contacting, and vortex shedding on the back side might influence the performance; their impact has not been evaluated.

- The uncertainties of Nusselt number and Fanning friction factor for the micro pin fin structure is below $7 \%$ and $6 \%$, respectively.

- The micro pin fin wire structure shows twice the heat transfer coefficient and twice the pressure drop compared to a louvered fin reference; thus a more compact heat exchanger with similar performance and less material usage is conceivable.

Author Contributions: Conceptualization, H.F. and P.D.L.; Data curation, H.F.; Formal analysis, H.F.; Investigation, H.F. and A.S.; Methodology, H.F.; Software, H.F.; Supervision, H.F. and L.S.; Visualization, H.F.; Writing—original draft, H.F.; Writing—review \& editing, P.D.L., A.S. and L.S.

Acknowledgments: The authors acknowledge the financial support from the German Federal Ministry of Education and Research (BMBF) for the Optimat Project (FKZ 03SF0492A). The authors thank the students Malte Niemeyer and Danny Carvajal for assembling the test rig and carrying out measurements, respectively.

Conflicts of Interest: The authors declare no conflict of interest.

\section{Nomenclature}

\begin{tabular}{|c|c|}
\hline$A$ & area $\left(\mathrm{m}^{2}\right)$ \\
\hline$c_{p}$ & specific heat $(\mathrm{J} / \mathrm{kg} \cdot \mathrm{K})$ \\
\hline$d$ & diameter, thickness or characteristic length $(\mathrm{m})$ \\
\hline $\mathrm{f}$ & Fanning friction factor \\
\hline$H$ & height $(\mathrm{m})$ \\
\hline$h$ & convection heat transfer coefficient $\left(\mathrm{W} / \mathrm{m}^{2} \mathrm{~K}\right)$ \\
\hline$k$ & thermal conductivity $(\mathrm{W} / \mathrm{m} \mathrm{K})$ \\
\hline$L$ & length $(\mathrm{m})$ \\
\hline$l$ & wire pitch $(\mathrm{m})$ \\
\hline$\dot{m}$ & mass flow rate $(\mathrm{kg} / \mathrm{s})$ \\
\hline$n$ & number of wires or fins \\
\hline $\mathrm{Nu}$ & Nusselt number \\
\hline$P$ & power $(W)$ \\
\hline$p$ & pressure $(\mathrm{Pa})$ \\
\hline$\dot{Q}$ & heat transfer rate $(\mathrm{W})$ \\
\hline $\operatorname{Re}$ & Reynolds number \\
\hline$T$ & temperature $(\mathrm{K})$ \\
\hline$\Delta T$ & temperature difference $(\mathrm{K})$ \\
\hline$U$ & overall heat transfer coefficient $\left(\mathrm{W} / \mathrm{m}^{2} \mathrm{~K}\right)$ \\
\hline$V$ & volume $\left(\mathrm{m}^{3}\right)$ \\
\hline$\dot{V}$ & volume flow rate $\left(\mathrm{m}^{3} / \mathrm{s}\right)$ \\
\hline$v$ & velocity \\
\hline$x$ & humidity ratio $(\mathrm{kg} / \mathrm{kg})$ \\
\hline \multicolumn{2}{|c|}{ Greek Symbols } \\
\hline$\beta$ & heat transfer surface area density $\left(\mathrm{m}^{2} / \mathrm{m}^{3}\right)$ \\
\hline$\delta$ & thickness of walls or fins (m) \\
\hline$\epsilon$ & effectiveness \\
\hline$\mu$ & dynamic viscosity (kg/m s) \\
\hline$\eta_{0}$ & extended surface efficiency \\
\hline$\eta_{\text {fin }}$ & fin efficiency \\
\hline$\rho$ & density $\left(\mathrm{kg} / \mathrm{m}^{3}\right)$ \\
\hline$\phi$ & porosity \\
\hline \multicolumn{2}{|c|}{ Subscripts } \\
\hline air & air side \\
\hline ch & characteristic value \\
\hline channel & domain before and after the test core \\
\hline cond & air flow conditioning system \\
\hline eff & effective \\
\hline
\end{tabular}




$\begin{array}{ll}\text { el } & \text { electric } \\ \text { in } & \text { inlet } \\ \text { fins } & \text { related to one or several (louvered) fins } \\ \text { HTS } & \text { heat transfer surface } \\ \text { HX } & \text { heat exchanger } \\ \text { HXelm } & \text { heat exchanger element (without header) } \\ \text { lat } & \text { perpendicular to the air flow direction; lateral } \\ \text { long } & \text { in air flow direction; longitudinal } \\ \text { m } & \text { mean } \\ \text { meas } & \text { measured value } \\ \text { out } & \text { outlet } \\ \text { p } & \text { primary surface; tube or plate wall } \\ \text { saplt } & \text { sample plate } \\ \text { st } & \text { domain between tubes for heat transfer enhancement structure } \\ \text { wire } & \text { related to one or several wires }\end{array}$

\section{Appendix A Fin Efficiency and Extended Surface Efficiency}

The fin efficiency $\eta_{\text {fin }}$ of plate-fin and tube-fin geometries of uniform fin thickness is given in [20] by:

$$
\eta_{\text {fin }}=\frac{\tanh (m l)}{m l}
$$

For the pin fins the parameters $m$ and $l$ are:

$$
\begin{gathered}
m=\left(\frac{4 h_{\text {air }}}{k_{\text {fin }} d_{\text {wire }}}\right)^{0.5}=\frac{2}{d_{\mathrm{ch}}}\left(\frac{d_{\mathrm{ch}}}{d_{\text {wire }}} \mathrm{Nu}_{\text {air }} \frac{k_{\mathrm{air}}}{k_{\text {fin } f \text { in }}}\right)^{0.5}, \\
l=\frac{H_{\mathrm{st}}}{2}-d_{\text {wire }}=\left(\frac{H_{\mathrm{st}}}{2 d_{\mathrm{ch}}}-\frac{d_{\text {wire }}}{d_{\mathrm{ch}}}\right) d_{\mathrm{ch}} .
\end{gathered}
$$

The product of $m$ and $l$ is:

$$
m l=\left(\frac{d_{\mathrm{ch}}}{d_{\text {wire }}} \mathrm{Nu}_{\text {air }} \frac{k_{\text {air }}}{k_{\text {fin }}}\right)^{0.5}\left(\frac{H_{\text {st }}}{d_{\text {ch }}}-\frac{2 d_{\text {wire }}}{d_{\text {ch }}}\right) .
$$

For the louvered fins, the calculation of $m$ and $l$ is similar (see details in [20]). The extended surface efficiency $\eta_{0}$ is given in [20] as:

$$
\eta_{0}=1-\frac{A_{\text {fin }}}{A}\left(1-\eta_{\text {fin }}\right)
$$

with:

$$
\frac{A_{\text {fin }}}{A}=1-\frac{A_{\mathrm{p}}}{A}=1-\frac{A_{\mathrm{p}}}{V_{\mathrm{HXelm}}} \frac{1}{\beta} \approx 1-2 \frac{d_{\mathrm{ch}}}{H_{\mathrm{st}}} \frac{1}{d_{\mathrm{ch}} \beta} .
$$

Such that $\eta_{0}$ is a function of geometry, material relation $k_{\text {air }} / k_{\text {fin }}$ and Nusselt number $\mathrm{Nu}_{\text {air }}$. Thus the reduction of variables yields:

$$
\eta_{0}=\text { function }\left(\mathrm{Nu}_{\mathrm{air}}, \frac{k_{\mathrm{air}}}{k_{\mathrm{fin}}}, \frac{d_{\mathrm{ch}}}{H_{\mathrm{st}}}, d_{\mathrm{ch}} \beta, \frac{d_{\mathrm{wire}}}{d_{\mathrm{ch}}}\right)
$$

for which all input variables are non-dimensional.

\section{References}

1. Tian, J.; Kim, T.; Lu, T.J.; Hodson, H.P.; Queheillalt, D.T.; Sypeck, D.J.; Wadley, H. The effects of topology upon fluid-flow and heat-transfer within cellular copper structures. Int. J. Heat Mass Transf. 2004, 47, 3171-3186. [CrossRef]

2. Girlich, D. Grundsatzuntersuchungen zum Einsatz Offenporiger Metallschäume in der Luft-, Kälte- und Wärmetechnik Abschlussbericht; Laufzeit: 01.11.2002 bis 31.10.2004; M-Pore GmbH: Dresden, Germany, 2006.

3. Hutter, C.; Büchi, D.; Zuber, V.; Rudolf von Rohr, P. Heat transfer in metal foams and designed porous media. Chem. Eng. Sci. 2011, 66, 3806-3814. [CrossRef]

4. Boomsma, K.; Poulikakos, D.; Zwick, F. Metal foams as compact high performance heat exchangers. Mech. Mater. 2003, 35, 1161-1176. [CrossRef] 
5. Iwai, H.; Kawakami, S.; Suzuki, K.; Tsujii, J.; Abiko, T. Performance Evaluation of Wire Spring Fin for Compact Plate-Fin Heat Exchangers. In Proceedings of the Enhanced, Compact and Ultra-Compact Heat Exchangers: Science, Engineering and Technology, Whistler, BC, Canada, 11-16 September 2005.

6. Sypeck, D.J.; Wadley, H.N.G. Multifunctional microtruss laminates: Textile synthesis and properties. J. Mater. Res. 2001, 16, 890-897. [CrossRef]

7. Xu, J.; Tian, J.; Lu, T.J.; Hodson, H.P. On the thermal performance of wire-screen meshes as heat exchanger material. Int. J. Heat Mass Transf. 2007, 50, 1141-1154. [CrossRef]

8. Liu, Y.; Xu, G.; Luo, X.; Li, H.; Ma, J. An experimental investigation on fluid flow and heat transfer characteristics of sintered woven wire mesh structures. Appl. Therm. Eng. 2015, 80, 118-126. [CrossRef]

9. Prasad, S.B.; Saini, J.S.; Singh, K.M. Investigation of heat transfer and friction characteristics of packed bed solar air heater using wire mesh as packing material. Sol. Energy 2009, 83, 773-783. [CrossRef]

10. Li, C.; Wirtz, R.A. Development of a High Performance Heat Sink Based on Screen-Fin Technology; University of Nevada: Reno, NV, USA, 2003.

11. Van Andel, E. Heat Exchanger and Method for Manufacturing Same. Patent Application No. EP0714500 B1, 7 January 1999.

12. Bonestroo, J.P. Calculation Model of Fine-Wire Heat Exchanger. Master's Thesis, Twente University, Enschede, The Netherlands, 2012.

13. Sahiti, N. Thermal and Fluid Dynamic Performance of Pin Fin Heat Transfer Surfaces. Ph.D. Thesis, Universität Erlangen, Nürnberg, Germany, 2006.

14. Fugmann, H.; Laurenz, E.; Schnabel, L. Wire Structure Heat Exchangers-New Designs for Efficient Heat Transfer. Energies 2017, 10, 1341. [CrossRef]

15. Petroski, S.J. An Investigation of the Performance of Confined, Saw-Tooth Shaped Wire-On-Tube Condensers; Air Conditioning and Refrigeration Center, College of Engineering, University of Illinois: Champaign, IL, USA, 1999.

16. Kim, T.; Zhao, C.Y.; Lu, T.J.; Hodson, H.P. Convective heat dissipation with lattice-frame materials. Mech. Mater. 2004, 36, 767-780. [CrossRef]

17. Verein Deutscher Ingenieure. In Wärmeatlas, 9th ed.; Springer: Berlin/Heidelberg, Germany, 2002.

18. Fugmann, H.; Oltersdorf, T.; Schnabel, L. Metal Wire Structures as Heat Transfer Surface Area Enlargement-Design Study and Potential Analysis for Air-to-Water Heat Pumps. In Proceedings of the 12th IEA Heat Pump Conference, Rotterdam, The Netherlands, 15-18 May 2017.

19. Fugmann, H.; Tahir, A.J.; Schnabel, L. Woven Wire Gas-To-Liquid Heat Exchanger. In World Congress on Mechanical, Chemical and Material Engineering; MCM15; Avestia Publishing, International ASET Inc.: Ottawa, ON, Canada, 2015.

20. Shah, R.K.; Sekulić, D.P. Fundamentals of Heat Exchanger Design; Wiley: Hoboken, NJ, USA, 2003.

21. GUM. Guide to the Expression of Uncertainty in Measurement (Deutsche Übersetzung); DIN Deutsches Institut für Normung e.V.: Berlin, Germany, 1999.

22. Fugmann, H.; Schnabel, L.; Frohnapfel, B. Heat Transfer and Pressure Drop Correlations for Laminar Flow in an In-line and Staggered Array of Circular Cylinders. 2018; in press.

23. Kim, M.-H.; Bullard, C.W. Air-side thermal hydraulic performance of multi-louvered fin aluminum heat exchangers. Int. J. Refrig. 2002, 25, 390-400. [CrossRef]

(C) 2018 by the authors. Licensee MDPI, Basel, Switzerland. This article is an open access article distributed under the terms and conditions of the Creative Commons Attribution (CC BY) license (http://creativecommons.org/licenses/by/4.0/). 